\title{
Determination of the working gap and optimal machining parameters for magnetic assisted ball burnishing
}

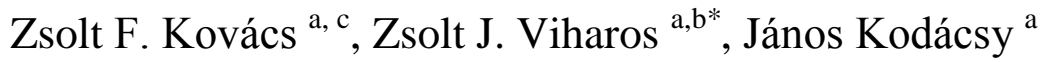 \\ ${ }^{a}$ John von Neumann University, GAMF Faculty of Engineering and Computer Science, Dep. of Vehicle Technology, Kecskemét H-6000 Hungary \\ ${ }^{b}$ Institute for Computer Science and Control of the Hungarian Academy of Sciences, Budapest H-1111 Hungary \\ ${ }^{c}$ Department of Manufacturing Science and Technology, Budapest University of Technology and Economics, Budapest H-1111 Hungary
}

\section{A R T ICLE INFO}

\section{Article history:}

Received 00 December 00

Received in revised form 00 January 00

Accepted 00 February 00

\section{Keywords:}

Magnetic

Ball burnishing

Surface roughness

Taguchi

Tribology

\begin{abstract}
A B S T R A C T
This paper presents the results of various experimental analysis regarding a permanent Magnetic Assisted Ball Burnishing (MABB) tool. This type is a special tool using the magnetic field to produce the necessary force for burnishing, it is applicable especially to rolling flat and 3D harmonic surfaces. For the correct operation of this special kind of tool, the set up for optimal distance between the tool and workpiece was introduced also taking into the account the measured rolling force $\left(\mathrm{F}_{\mathrm{z}}\right)$, which occurs between the tool and workpiece because the magnetic force pulls the rolling balls on a cone which is located at the end of the tool. In this paper the optimisation of the process parameters for burnishing of $\mathrm{C} 45$ normalized premachined steel is also presented. To determine the dominant machining parameters the resulted surface roughness and the tribological parameters were also anaysed. The evaluation was completed by advanced measuring and IT equipment.
\end{abstract}

(C) 2017 Elsevier Ltd. All rights reserved.

\section{Introduction}

"One of the most competent surface engineering methods i.e. mechanical treatment, is the burnishing process" [1]. There are several type of burnishing, like roller burnishing [2], ball burnishing [2] or diamond burnishing [3]. There are also some technologies which are similar to them, for example shot peening [4] and not to mention the special processes like laser-assisted burnishing which is able to burnish high hardness (45-60 HRC) metals [5].

Nowadays the ball burnishing processes have become more accepted as a post machining, metal finishing operation [6], the main aim of conventional ball or roller burnishing is to achieve high-quality surfaces. All surfaces of mechanical parts can be considered as valleys and peaks. During the process one or more balls makes plastic deformation on the surface layer. In the case, if this stress is higher than yield strength of the material, the material near the surface starts to flow [7, 8]. In this state, there is a possibility that it may lead to plastic deformation of higher asperities contacted, having the modest effect on the surface quality. It may cause severe wearing behavior which thanks to the burnishing processes increase the hardness and decrease the roughness of the machined surface [1].

As the balls moves across the surface of workpiece, the peaks of surface are pressed down into the material and it flows into the valleys between the peaks as it is presented in Fig. 1. [7, 8, 9].

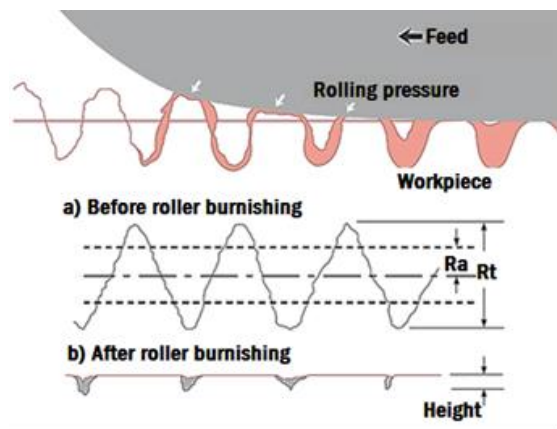

Fig. 1. Evolution of surface by burnishing [7] 
Several studies have investigated the effect of burnishing on the workpiece properties (e.g. increasing the residual stress, hardness, corrosion and wear resistance further to enhance the fatigue life and surface quality) $[10,11,12]$. Because its's simplicity and economical effectiveness, the burnishing is a widely used cold treatment/machining process. The type of burnishing process depends on the form of the workpiece (e.g. flat or cylindrical). In the paper a newly designed and introduced flat-surface ball burnishing tool was examined. The burnishing of flat or 3D harmonic surfaces needs special tools and/or equipment (e.g. hydraulic hose and pump) e.g. F. Gharbi, S. Sghaier and T. Benameure designed a tool, which consist of four burnishing tools which are adapted in a special tool holders (Fig. 2.) [13].

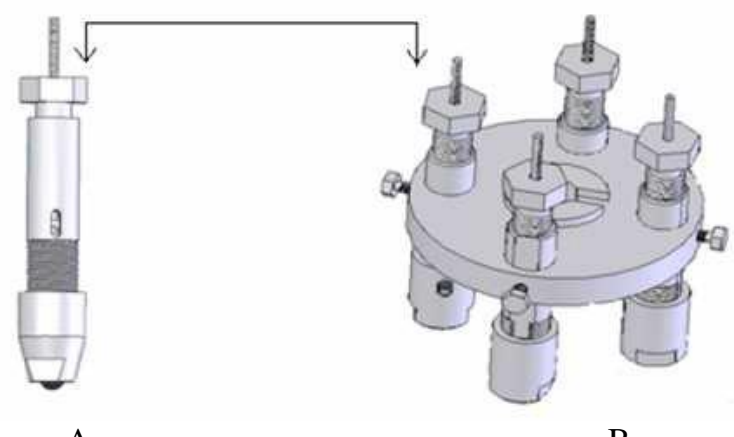

A

B

Fig. 2. (A) The simple ball burnishing tool and the (B) tool holder with four ball burnishing tools [13]

The main problem with most of the burnishing tools (such as in Fig.2.) is their applicability in a CNC machine because it is difficult to place them into the tool magazine, in Table 1. the advantages and drawbacks of various burnishing technologies are compared.

Table 1.

Cold metal working surface improvement technologies

\begin{tabular}{ccc}
\hline Technology & Advantages & Drawbacks \\
\hline $\begin{array}{c}\text { Roller } \\
\text { burnishing [2] }\end{array}$ & cheap tool & $\begin{array}{c}\text { only cylindrical } \\
\text { workpiece }\end{array}$ \\
$\begin{array}{c}\text { Ball } \\
\text { burnishing [3] }\end{array}$ & $\begin{array}{c}\text { cylindrical and } \\
\text { flat workpiece }\end{array}$ & expensive tool \\
$\begin{array}{c}\text { Diamond } \\
\text { burnishing [4] }\end{array}$ & hard workpiece & rigid tool \\
Shot peening [5] & $\begin{array}{c}\text { 3D contoured } \\
\text { surfaces }\end{array}$ & $\begin{array}{c}\text { required special } \\
\text { equipment }\end{array}$ \\
\hline
\end{tabular}

Considering drawbacks of expensive and complicated construction, the authors designed a novel Magnetic Assisted Ball Burnishing (MABB) tool. During the design process, the Magnetism Aided Machining or Magnetic Assisted Machining (MAM) technologies were investigated $[14,15,16,17,18]$, which are relatively novel industrial machining processes. The MAM technologies are mainly suitable for finishing and surface improvements. The MABB tool was developed to reduce the surfaces roughness increasing the surface hardness and deburring the edge of flat (in some cases even 3D harmonic surfaces) metal parts. The magnetic force makes this process simple, productive and environmental friendly, it is generated by the magnetic field between the workpiece and the tool, so, it is so important to set up the right tool-workpiece distance to ensure the optimal rolling pressure [19].

Several machining parameters, namely burnishing speed, feed rate, force, number of burnishing passes, workpiece material and hardness, ball material, ball size, number of balls and lubricant have to be considered to define an effective and efficient burnishing process [20, 21].

A.M. Hassan and A.S. Al-Bsharat presented in their research that the burnishing forces and the number of tool passes are predominant parameters that have effect on the surface roughness of the workpiece during the burnishing process [22].

Taking into the account that the introduced ball burnishing technology is a novel solution, it has to be positioned among other techniques having similar manufacturing aims (e.g. as in Table 1.), moreover it has to be characterized and it's capabilities have to be qualified by various measuerements. The analyzed ball burnishing technology improves the tribological features of the machined surface significantly. The most frequently used charcterization features of a surface from triboloical point of view are the $R_{s k}$ and $R_{k u}$ roughness parameters, consequently, these quantification measures were used to describe the effectiveness of the proposed ball burnishing soultion. The experiments proved also that a more favourable solution is the application of the rotating dynamometer instead of a multicomponent dynanometer and it can be used for measuring the burnishing force and also in the optimisation of the working gap and the technological parameters, too.

\section{Magnetic assisted ball burnishing tool}

The novel MABB tool contains four magnetizable bearing balls and the magnetic force pulls these balls to a cone which is located at the end of tool and this construction results in the necessary $F_{z}$ rolling force $\left(F_{z}\right.$ in Fig. 3.).

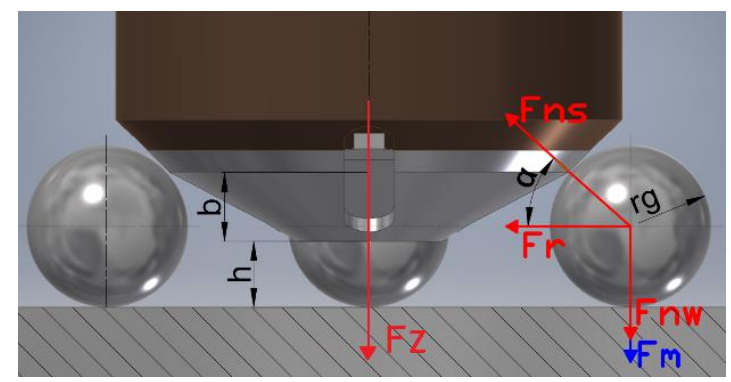

Fig. 3. The generated force during ball burnishing

The first generation of MABB tools are working with an electromagnet (Fig. 4.). The constructions' main advantages are the adjustable magnetic force which gives less importance to the gap distance. But this adjustable 
function causes problem in the usability, because it requires electric cables feed to the tool during machining, so it is not advantageous to a modern CNC machine. Furthermore, the electromagnetic coil heats up during machining and, as a result, decreases the magnetic field strength [23].

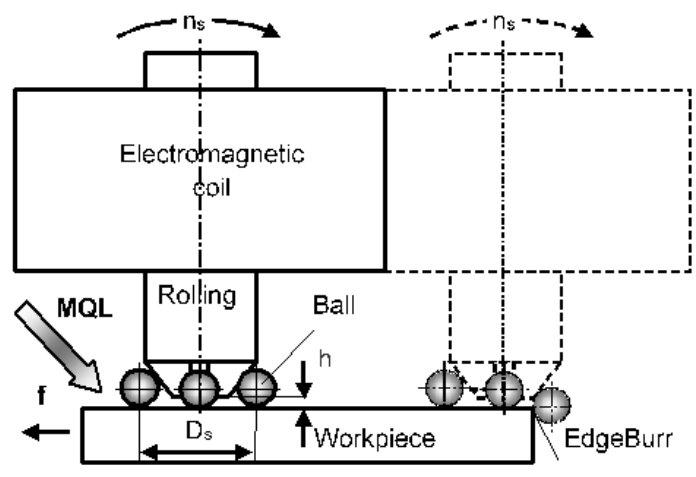

Fig. 4. Concept of the electro MABB tool [23]

The new MABB tool works with $\mathrm{NdFeB}$ permanent magnet instead of the electromagnet (Fig. 5.). Thanks to the permanent magnet design, the tool can be placed into the tool magazine, removing edge burr and following the topology of surface.

In a recent study M.M. El-Khabeery and M.H. El-Axir they identified some of the main effects of the burnishing. Their results are useful and contains essential statements (e.g. the burnishing speed should not exceed about 120 $\mathrm{m} / \mathrm{min}$ to obtain high surface quality), but as it was mentioned also the tool gap has great significance and so it must be an optimum value [24]. Many further research studies have been conducted to investigate the effects of burnishing feed, speed and force on surface roughness during burnishing process $[25,26,27]$.

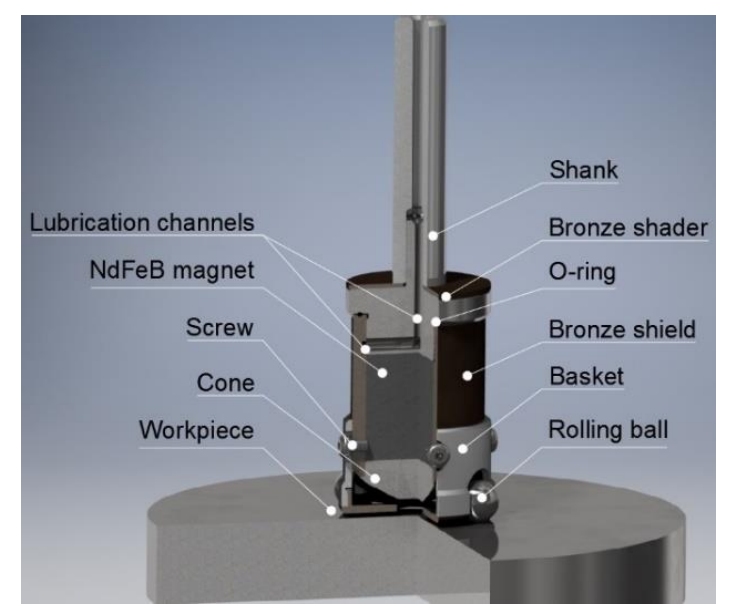

Fig. 5. Parts of permanent MABB tool

High burnishing force is required to achieve low roughness. Because the introduced MABB tool is a novel solution, so, the optimal working gap distance resulting in the highest burnishing force is unknown. This parameter was determined by calculation (Paragraph 3) and experiments (Paragraph 4.), too. The experiments consisted in two parts. Since the centrifugal force on the balls decreases the pressure of them to the surface, so, the first test was performaed by a standing tool, (first part in Paragraph 4.) and in the second paert of the analysis the tool was rotating (second part in Paragraph 4.). The search for the optimal machining parameters were done applying the classical Taguchi experimental design method using the already predetermined optimal working gap (described in Paragraph 5.).

\section{Determination of working gap by calculation}

The optimum working gap $(h)$ between the tool and workpiece can be determined by calculation and experiments, too. The tool geometrical parameters are: ballradius $\left(r_{\mathrm{g}}=8 \mathrm{~mm}\right)$ and cone height $(b=5 \mathrm{~mm})$ so they can be used in the equations (1) and (2) in relation to Fig. 3. vectors:

$$
\begin{aligned}
& h=r_{g} \cdot(\sin \alpha+1)-b \\
& F_{n w}=F_{r} \cdot \tan \alpha
\end{aligned}
$$

where $F_{\text {nw }}$ the burnishing force per ball and $F_{\mathrm{r}}$ is the radial magnetic attraction force. The Fig. 3 also represents the vectors of the resulting force of $F_{\mathrm{r}}\left(F_{\mathrm{ns}}\right)$ and the attraction force of workpiece $\left(F_{\mathrm{m}}\right)$, but the recent is negligible.

The equalization of (1) and (2):

$$
F_{n w}=F_{r} \cdot \tan \cdot\left(\arcsin \left(\left(\frac{h+b}{r_{g}}\right)-1\right)\right)
$$

In equation (3) the $F_{\mathrm{r}}$ is constant, because there is no change in the permeability of the ball and the gradient of magnetic field during the rolling. The calculations are initiated with $h=4 \mathrm{~mm}$ gap and tested up to $h=12 \mathrm{~mm}$.

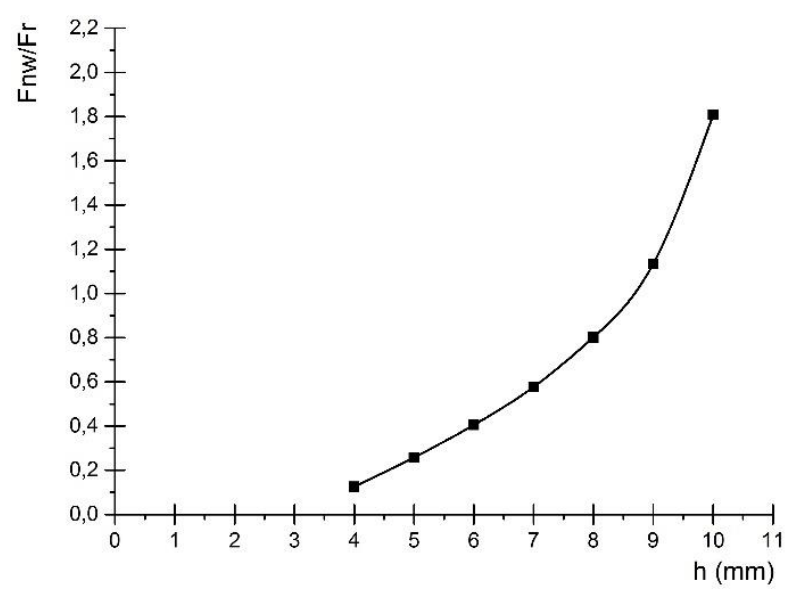

Fig.6. The relationship between $h$ and $F_{\mathrm{nw}} / F_{\mathrm{r}}$ by calculations

Under the $h=4 \mathrm{~mm}$ gap the balls can fly away, because the balls reach the tool edge which made from bronze and they cannot be affected by the magnetic field. Reaching the 
$h=11 \mathrm{~mm}$ gap and the $\alpha=90^{\circ}$ there is no solution for the tangent calculation. Using the equations a graph representing the relation beween $h$ and $F_{\mathrm{nw}} / F_{\mathrm{r}}$ is determined (Fig. 6.).

According to the calculation, the optimum gap distance for the highest burnishing force is about h=10mm.

\section{Determinning of the working gap by experiment}

Results of calculations may differ from the reality, therefore the determination of the optimal gap is carried out by experiments, too. For the experiments a CNC milling machine and a KISTLER Type 9125A24A2 force and torque measuring instrument were used (Fig. 7.) during setup and machining processes.

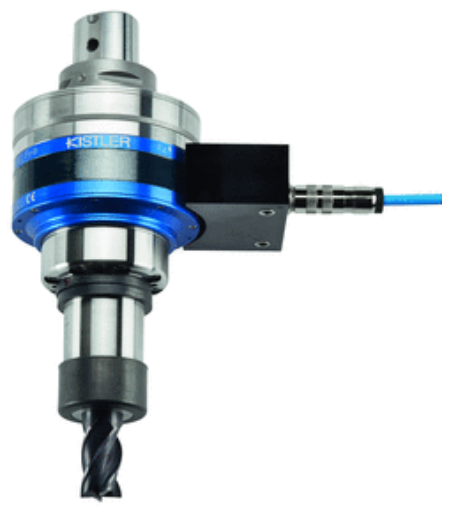

Fig. 7. KISTLER rotating dynamometer with end mill [28]

The measuring took $100 \mathrm{sec}$ while the sampling rate was $500 \mathrm{~Hz}$. The measuring range of $F_{\mathrm{z}}$ was set up between $400-700 \mathrm{~N}$.

To avoid accidents, as a first step, the tool was tested in a standing position (without the main rotating movement) and after knowing the optimum gap, the rolling force was measured continuously while the tool was rotating.

\subsection{Standing tool}

The results of the calculations were used for the experiments, so the starting position with standing balls was the maximum of $h=11 \mathrm{~mm}$ gap and it was tested down to $h=4 \mathrm{~mm}$. The measurement arrangement is shown in Fig. 8 .

The measurement started in $\mathrm{h}=14 \mathrm{~mm}$, without balls, then the balls were placed into their positions and the tool moved away from the surface with $1 \mathrm{~mm}$ steps. The result of the measurements are shown in Fig. 9.

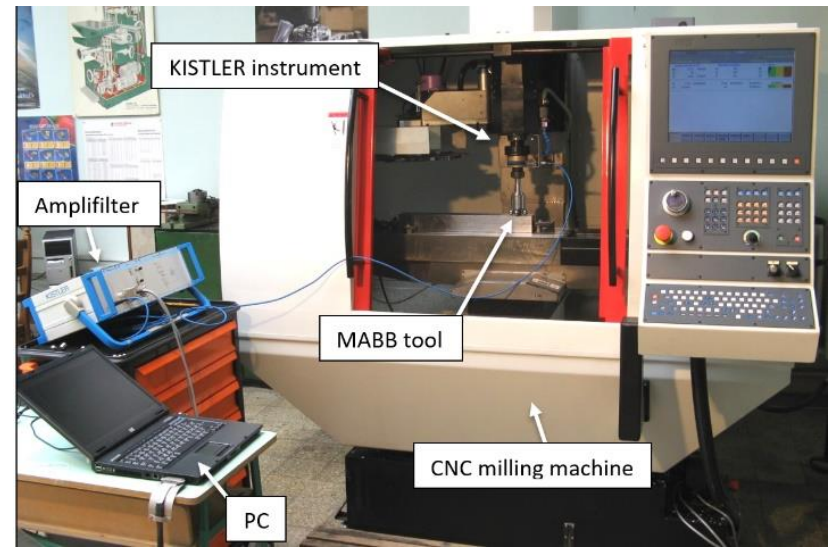

Fig. 8. Experimental setup of the force measuring

As represented in Fig. 9. without balls, the tool attracts the workpiece, consequently, this is the reason for the small negative $\mathrm{F}_{\mathrm{z}}$ force. After placing the balls into the workspace, the tool began pushing the workpiece through the balls. As it is represented in Fig. 9., the maximum force arose with $h=10 \mathrm{~mm}$ gap and under $h=6 \mathrm{~mm}$ the $\mathrm{F}_{\mathrm{z}}$ force will be again negative. This means that here the tool started to attract again the workpiece by the balls and also by the cone of the tool, too.

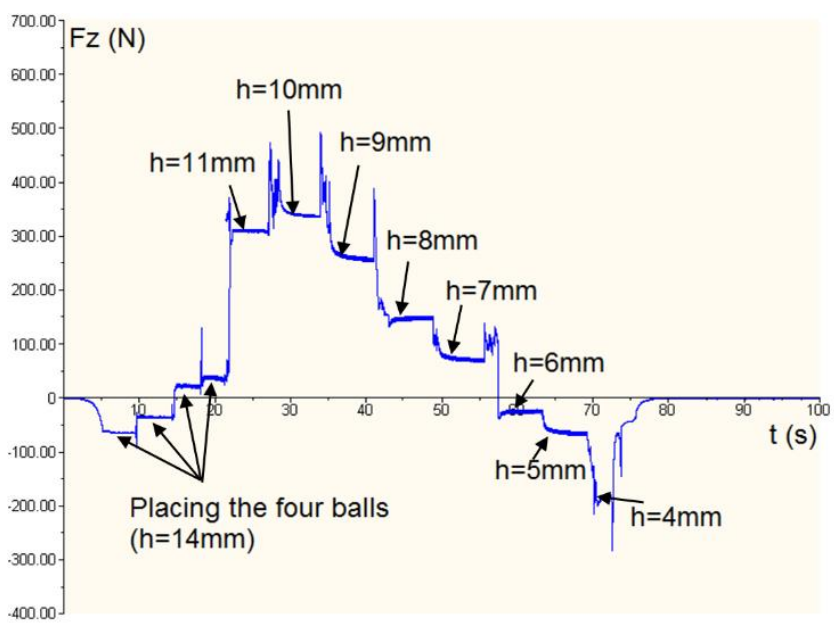

Fig. 9.The magnetic force depending on the tool distance

According to the expectations and the calculation, the maximal force $\left(\mathrm{F}_{\mathrm{z}}=350 \mathrm{~N}\right)$ was measured at $\mathrm{h}=10 \mathrm{~mm}$. Because there are four balls, force of $87,5 \mathrm{~N}$ per ball with standing tool is resulted.

\subsection{Rotating tool}

The main problem with a rotation is that it increases the centrifugal force which can significantly reduce the burnishing force, moreover, under special conditions the balls can fly away. In order to avoid it, the rolling force was measured during increasing revolution, from 0 to 1400 rev/min. The measured $F_{z}$ values are summarized in Fig. 10. 


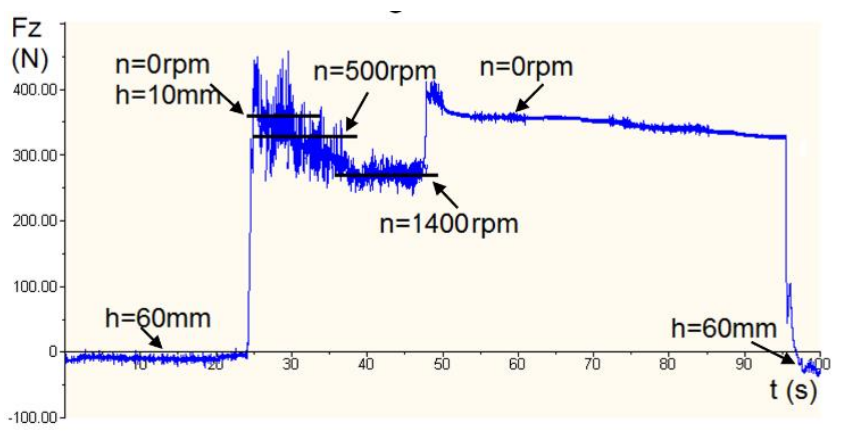

Fig. 10. Magnetic force depending on the revolution speed

As the Fig. 10. shows the effect of increasing revolution, that resulted in decrease of the rolling force from $350 \mathrm{~N}$ to $260 \mathrm{~N}$, it shows that the force was decreased by $25 \%$. This decline is not a very significant value and in the practice experts never use higher revolution than 1400rev/min, because the higher revolution negatively affects the quality of the surface, too [24]. Consequently, the tool can be safely used until $1400 \mathrm{rev} / \mathrm{min}$. In practice, the best revolution range is between $150-500 \mathrm{rev} / \mathrm{min}$ [20].

\section{Optimisation of machining by experiments}

The influence of roller burnishing parameters on the machined surface roughness was experimentally studied applying gap set-ups around the the previously determined, optimal value. Beside the gap distance the rolling speed $\left(v_{\mathrm{r}}\right)$ and feed $\left(v_{\mathrm{f}}\right)$ technological parameters have the main effects on surface roughness. In the consciousness of this the aim is to find optimal values for $v_{\mathrm{r}}$ and $v_{\mathrm{f}}$. The experimental details and procedures adopted to carry out the machining parameter's optimisation are summarized in the next paragraph.

\subsection{Experimental circumstances}

Testing sample was a C45-type hot rolled steel. The burnishing tool diameter was $\mathrm{D}=43 \mathrm{~mm}$, and the hardened (HRC60) bearing balls' diameters were $d=\varnothing 16 \mathrm{~mm}$ (Fig. 11.).

\section{Table 2}

Burnishing factors and levels

\begin{tabular}{|c|c|c|c|c|}
\hline & \multirow{2}{*}{ Burnishing factor } & \multicolumn{3}{|c|}{ Level } \\
\hline & & 1 & 2 & 3 \\
\hline A & Burnishing speed $\left(\mathrm{v}_{\mathrm{r}}\right)[\mathrm{m} / \mathrm{min}]$ & 20 & 40 & 60 \\
\hline B & Feed $\left(\mathrm{v}_{\mathrm{f}}\right)[\mathrm{mm} / \mathrm{min}]$ & 25 & 50 & 75 \\
\hline $\mathrm{C}$ & Tool gap $(h)[\mathrm{mm}]$ & 8,5 & 11,5 & 10 \\
\hline $\mathrm{D}$ & Premachined surface quality $\left(R_{a}\right)[\mu \mathrm{m}]$ & 0,950 & 0,672 & 1,105 \\
\hline
\end{tabular}

Three different categories of performance characteristics are usually used to calculate the SNR (Single to Noise ratio), depending whether in the applied Taguchi experimental design method for the optimisation target the lower (value) is the better, the higher is the better and the
The burnishing processes, as most of the all cold forming techniques, requires lubricant. Many types of oil can be used, in this experiment the Minimum Quantity Lubrication (MQL) system with $20^{\circ} \mathrm{E}$ synthetic oil was applied [29].

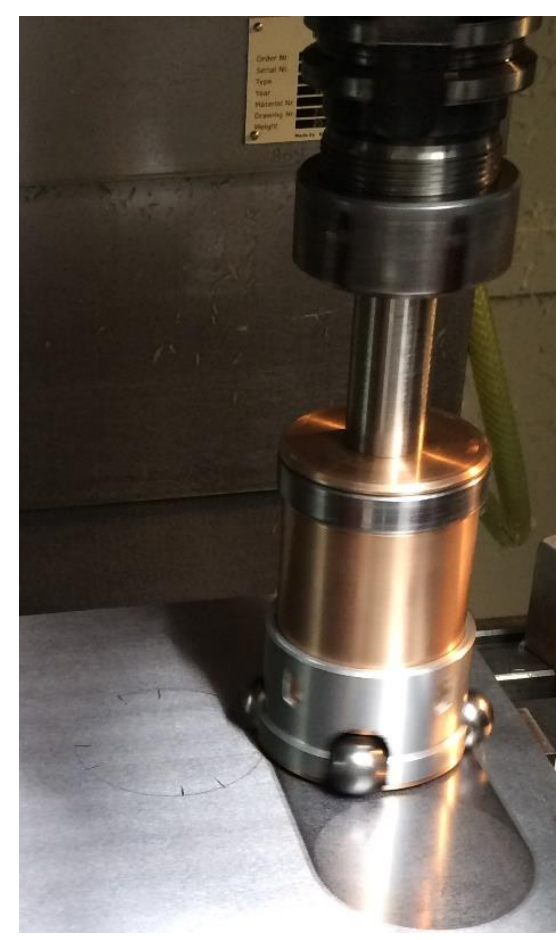

Fig. 11. The permanent MABB tool during machining

\subsection{Design of experiment (DoE)}

The primary goal was to determine ideas about effects of technological parameters on the burnished surfaces. The design of the experiments (DoE) provides suggestions how to efficiently perform experimentation to evaluate the effect of the process factors on the outcomes of the process.

The Taguchi DoE technique is a powerful tool for engineering design method and its dominant advantage is to remarkably reduce the number of experiments, so, it reduces the experimental cost and time by the use of an orthogonal array [30]. nominal is the better [31]. In the presented case, the higher is the better characteristic was used, because the process outcome to be evaluated was the improvement of the surface roughness after ball burnishing. 
The corresponding SNR is given by (4)

$\mathrm{SNR}=-10 \cdot \lg \frac{1}{n} \sum \frac{1}{y_{i j}{ }^{2}}$

where $y_{\mathrm{ij}}$ is the measured experimental result and $n$ is number of the experiments [31].

Using the calculated SNR, the effects of the process factors on the improvement of surface roughness by the MABB were evaluated. The selected burnishing factors and their levels are listed in Table 2 . In the practice and as determined above, the best revolution range is between 150-500 rev/min so, taking into consideration the tool diameter, the burnishing speed were 20,40 and $60 \mathrm{~m} / \mathrm{min}$. Based on this logic, set-up values for the feed were 25, 50 and $75 \mathrm{~mm} / \mathrm{min}$.

In the practice, the burnishing process is applied e.g. after milling, so the authors previously milled the workpiece by three feed parameters (since, feed has the most determinant effect on the resulted surface roughtness): 100, 200 and $300 \mathrm{~mm} / \mathrm{min}$ and these feed parameters have resulted in 0,$672 ; 0,950$ and $1,105 \mu \mathrm{m}$ for the Ra surface roughness. The cutting speed was set-up to $120 \mathrm{~m} / \mathrm{min}$ and the cutting depth was $1 \mathrm{~mm}$ in milling.

\subsection{Experimental results}

The optimal burnishing parameters studies were carried out as per the standard orthogonal array L9 $\left(3^{4}\right)$. The experimental results were analyzed through MINITAB 17 software tool that serves also with the related DoE table. The surface roughness, burnishing force and tribological features were studied by Origin Pro data analysis and graphical software.

The experiments guide were specified according to
Table 2 and then the surface roughness and burnishing force were evaluated by Taguchi method (Table 3.).

Table 3

Orthogonal array table for the designed experiments

\begin{tabular}{ccccc}
\hline \multirow{5}{*}{ No. } & \multicolumn{4}{l}{ Burnishing factor } \\
\cline { 2 - 5 } & A & B & C & D \\
\hline 1 & 20 & 25 & 8,5 & 0,950 \\
2 & 20 & 50 & 11,5 & 0,672 \\
3 & 20 & 75 & 10,0 & 1,105 \\
4 & 40 & 25 & 11,5 & 1,105 \\
5 & 40 & 50 & 10,0 & 0,950 \\
6 & 40 & 75 & 8,5 & 0,672 \\
7 & 60 & 25 & 10,0 & 0,672 \\
8 & 60 & 50 & 8,5 & 1,105 \\
9 & 60 & 75 & 11,5 & 0,950 \\
\hline
\end{tabular}

For evaluation (surface roughness and burnishing force) a surface roughness measuring equpiment (MITUTOYO Formtracer SV-C3000) was used for pre-machined as well as for burnished surfaces. Each surface was measured three times and the average of them are presented in the Table 4. The comparison of the pre-machined and burnished surfaces are shows in Fig. 12.

The Fig. 12. represents that after ball burnishing the peaks are pressed down while the valleys are filled up according to thematerial flow, but some of the valley were not filled up because they are too deep. These remaining valleys not harmful because these are function as oil pockets which results better sliding properties.

Table 4

Burnishing factors and levels

\begin{tabular}{|c|c|c|c|c|c|c|}
\hline No & $\begin{array}{l}\text { Ra before burnishing } \\
(\mu \mathrm{m})\end{array}$ & $\begin{array}{l}R a \text { after burnishing } \\
(\mu \mathrm{m})\end{array}$ & $\begin{array}{l}\text { Improvement of Ra } \\
(\mu \mathrm{m})\end{array}$ & $\begin{array}{l}\text { Singal to Noise }(S / N) \text { ratio } \\
\text { for surface roughness }(\mathrm{dB})\end{array}$ & $\begin{array}{l}\text { Burnishing } \\
\text { force }(\mathrm{N})\end{array}$ & $\begin{array}{l}\text { Singal to Noise }(S / N) \text { ratio } \\
\text { for burnishing force }(\mathrm{dB})\end{array}$ \\
\hline 1 & 0,950 & 0,159 & 0,791 & $-15,9721$ & 234,8 & 47,4140 \\
\hline 2 & 0,672 & 0,351 & 0,321 & $-9,0939$ & 227,3 & 47,1320 \\
\hline 3 & 1,105 & 0,580 & 0,525 & $-4,7314$ & 266,0 & 48,4976 \\
\hline 4 & 1,105 & 0,127 & 0,978 & $-17,9239$ & 228,2 & 47,1663 \\
\hline 5 & 0,950 & 0,256 & 0,694 & $-11,8352$ & 266,5 & 48,5139 \\
\hline 6 & 0,672 & 0,445 & 0,227 & $-7,0328$ & 247,4 & 47,8680 \\
\hline 7 & 0,672 & 0,159 & 0,513 & $-15,9721$ & 248,0 & 47,8890 \\
\hline 8 & 1,105 & 0,235 & 0,87 & $-12,5786$ & 229,0 & 47,1967 \\
\hline 9 & 0,950 & 0,204 & 0,746 & $-13,8074$ & 205,5 & 46,2562 \\
\hline
\end{tabular}



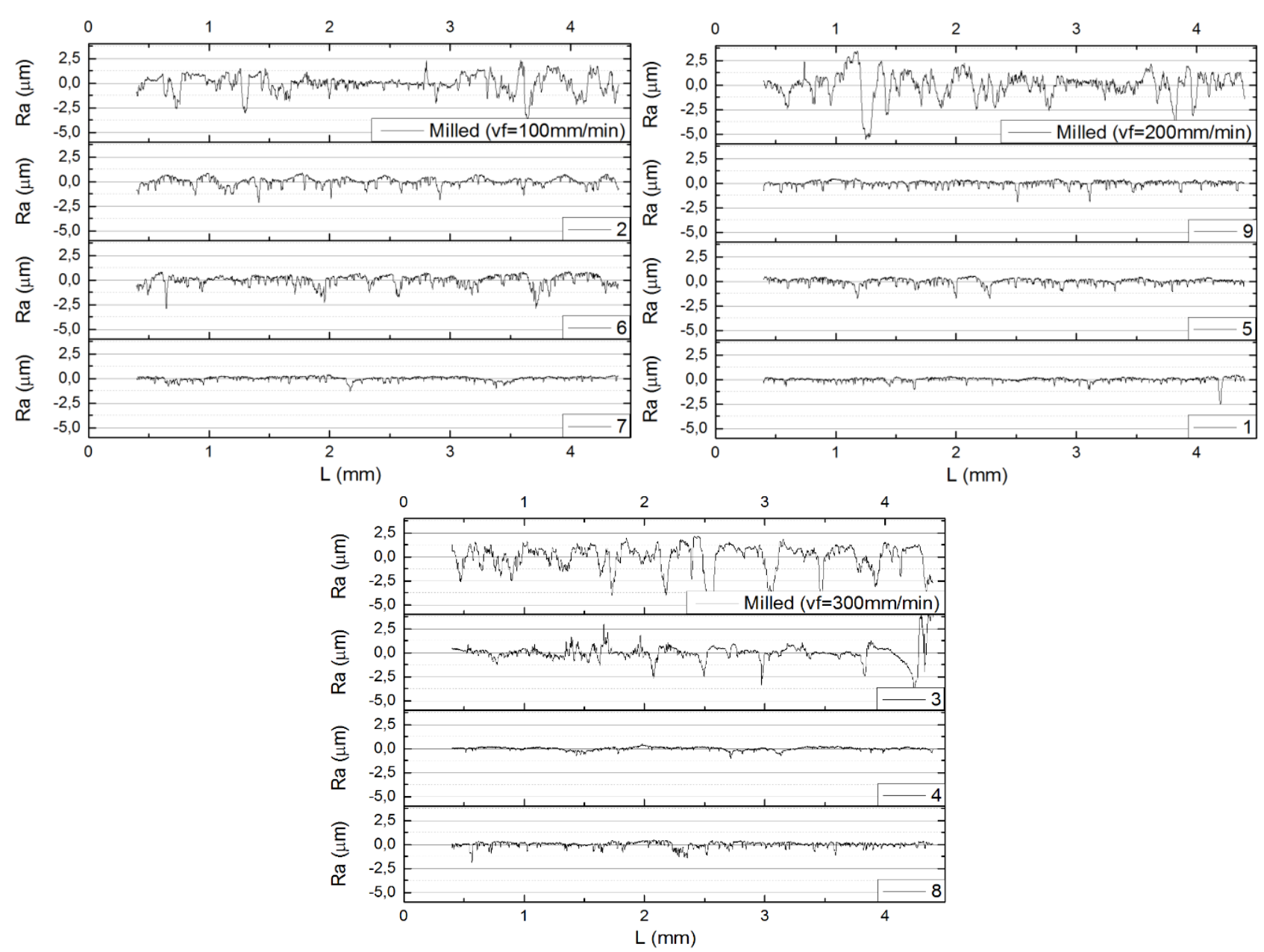

Fig. 12. Comparison of the pre-machined (with three different machining feed) and burnished surface roughness profiles measured three times

Table 5. shows the influence of the burnishing factor. This response table helps to get more information about the process under investigation since the highest delta value appoints the most influential factor. According to the results represented in this table, for surface roughness reduction the order of influence of the factors is: 1 . the burnishing feed, 2. burnishing speed, 3. pre-machined surface quality and 4. tool-workpiece gap.

Table 5

Influence of burnishing factor (depending on surface roughness)

\begin{tabular}{|c|c|c|c|c|c|}
\hline \multirow{2}{*}{ Factor } & \multicolumn{3}{|c|}{ Level } & \multirow{2}{*}{ Delta } & \multirow{2}{*}{ Rank } \\
\hline & 1 & 2 & 3 & & \\
\hline A & $-9,932$ & $-12,264$ & $-14,119$ & 4,187 & 2 \\
\hline B & $-16,623$ & $-11,169$ & $-8,524$ & 8,099 & 1 \\
\hline $\mathrm{C}$ & $-11,861$ & $-10,846$ & $-13,608$ & 2,762 & 4 \\
\hline D & $-10,700$ & $-13,872$ & $-11,745$ & 3,172 & 3 \\
\hline
\end{tabular}

The main effects of the burnishing factors on the surface roughness improvement after MABB processing are shown in Fig. 13. In the Taguchi method, higher SNR for the experimental results is desirable and the optimal conditions can be easily determined by selecting the combination of the maximal SNR in each factor.
As shown in Fig. 13. the determined optimal condition is a combination of A1-B3-C2-D1 ( $\mathrm{v}_{\mathrm{r}}: 20 \mathrm{~m} / \mathrm{min}-\mathrm{v}_{\mathrm{f}}$ : 75 $\left.\mathrm{mm} / \mathrm{min}-\mathrm{h}: 11,5 \mathrm{~mm}-\mathrm{R}_{\mathrm{a}}: 0,950 \mu \mathrm{m}\right)$ (Table 2.). This optimal combination was not tested in the previous experiments because the combination was not matched in Table 3.

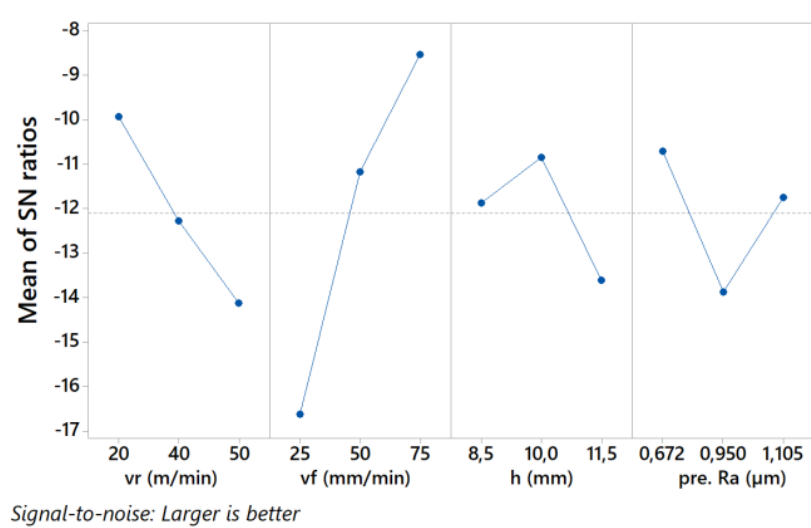

Fig. 13. Analysis of main effects of burnishing factor

The next response table (Table 6.) shows the most influenting factor for burnishing force improvement. 
Table 6

Influence of burnishing factor (depending on burnishing force)

\begin{tabular}{|c|c|c|c|c|c|}
\hline \multirow{2}{*}{ Factor } & \multicolumn{3}{|c|}{ Level } & \multirow{2}{*}{ Delta } & \multirow{2}{*}{ Rank } \\
\hline & 1 & 2 & 3 & & \\
\hline A & 47,68 & 47,85 & 47,11 & 0,74 & 2 \\
\hline B & 47,49 & 47,61 & 47,54 & 0,12 & 4 \\
\hline $\mathrm{C}$ & 47,49 & 48,30 & 46,85 & 1,45 & 1 \\
\hline D & 47,63 & 47,39 & 47,62 & 0,23 & 3 \\
\hline
\end{tabular}

In this case the most influenting factor for surface reduction in sequence: 1 . tool-workpiece gap, 2 . burnishing speed, 3. pre-machined surface quality and 4. burnishing feed.

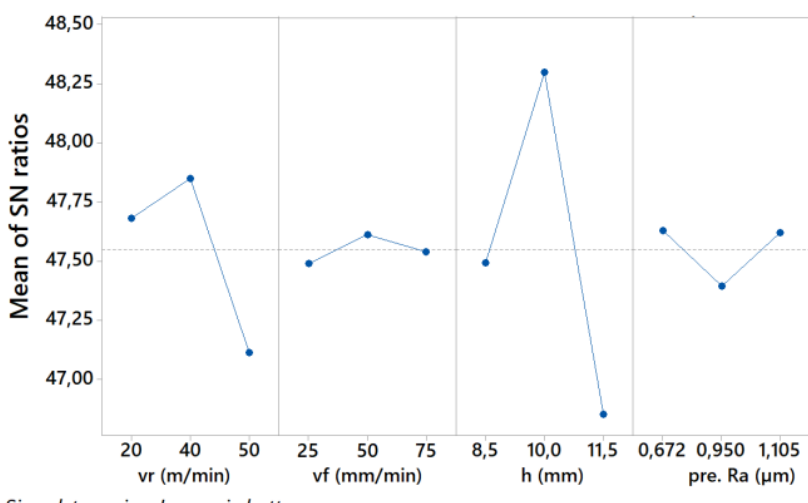

Signal-to-noise: Larger is better

Fig. 14. Analysis of main effects of burnishing factor

The main effect of the burnishing factors on the burnishing force is shown in Fig. 14., the determined optimal conditions are a combination of A2-B2-C2-D3 $\left(\mathrm{v}_{\mathrm{r}}\right.$ : $\left.40 \mathrm{~m} / \mathrm{min}-\mathrm{v}_{\mathrm{f}}: 50 \mathrm{~mm} / \mathrm{min}-\mathrm{h}: 11,5 \mathrm{~mm}-\mathrm{R}_{\mathrm{a}}: 1,105 \mu \mathrm{m}\right)$, that was not defined in Table 3 .

\subsection{Burnishing force}

In order to determine the $\left(\mathrm{F}_{\mathrm{z}}\right)$ burnishing force during the burnishing tests it was measured by the previously described force and torque measuring instruments. This measurement is important because it will help to get know the tool usability for 3D harmonic surfaces. The Fig. 15. shows trends of burnishing forces during the experiments.

The burnishing force highly depends on the toolworkpiece gap $(h)$, burnishing speed $\left(v_{\mathrm{r}}\right)$ and even the feed $\left(v_{\mathrm{f}}\right)$ (Fig. 15.) which is proved by the results of Table 6 , too.

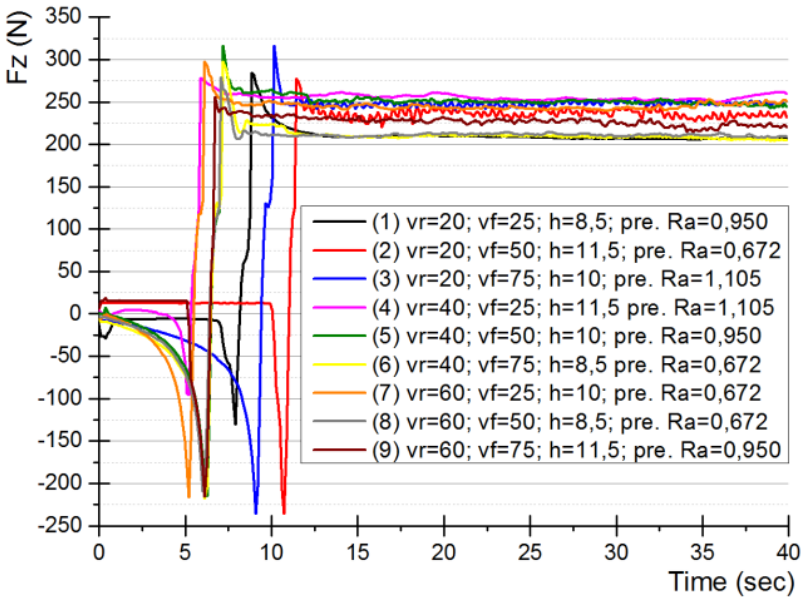

Fig. 15. Burnishing force measurements

\subsection{Analysis of tribological aspects}

In industrial practice the surface topography is one of the most critical factors and important indicators especially for the performance of high precision components. Some symptoms can be used to control the manufacturing process: changes in the surface texture, changes in the manufacturing process like machine tool vibration or tool wear. Furthermore, it helps to interpret functional properties of macro, micro and nanogeometry which directly impact on tribological system [32]. There are some tribology related roughness parameters such as $R_{\text {sk }}$ and $R_{k u}$ which strongly depend on the method of the manufacturing process.

The skewness $\left(R_{\text {sk }}\right)$ is a measure of the symmetry of the profile about the mean line, giving information on asymmetrical profiles for surfaces with the same values of $R_{a}$ and $R_{m s}$. Negative values of $R_{s k}$ indicate a predominance of troughs, while positive ones are observed for surfaces with peaks (Fig. 16.) [33].
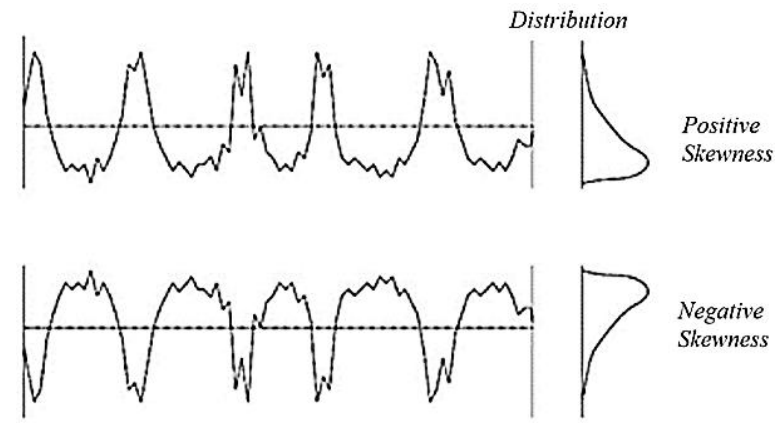

Fig. 16. Profile types of $\mathrm{R}_{\mathrm{sk}}[33]$

The Kurtosis $\left(\mathrm{R}_{\mathrm{ku}}\right)$ is a measure of the sharpness of the profile about the mean line that provides information on the distribution of spikes above and below the mean line. Thus, spiky surfaces will have a high kurtosis value $\left(\mathrm{R}_{\mathrm{ku}}>3\right)$ and bumpy surfaces a low value $\left(\mathrm{R}_{\mathrm{ku}}<3\right)$ (Fig. 17.) [33]. 

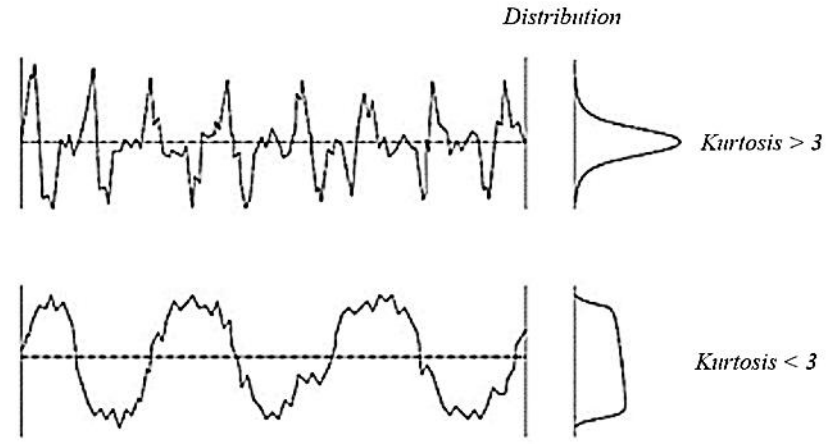

Fig. 17. Profile types of $\mathrm{R}_{\mathrm{ku}}$ [33]

The statistical index numbers of machined surface roughness are defined by the so-called topological map (Fig. 18.).

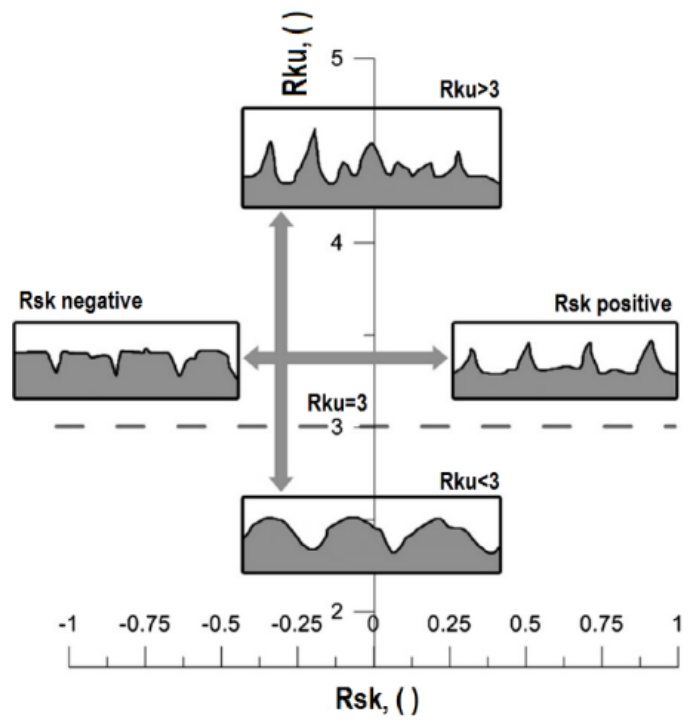

Fig. 18. Graphical representation of $\mathrm{R}_{\mathrm{sk}}$ and $\mathrm{R}_{\mathrm{ku}}$ topological map [34]

On the topological map in Fig. 19. the resulted $R_{\text {sk }}$ and $R_{k u}$ pair values of the surfaces machined with different manufacturing technologies can be seen [35].

The difference between these groups explains why surfaces machined with different technologies behave differently during operation. It is very important that only those technologies can be placed in the Fig. 19 which can create appropriate surface in tribological aspect. Therefore, technologies such as polishing or lapping cannot be placed because they lead to the stick-slip efect.

One of the aims of the paper is to place the introduced MABB technology on the classical topological map in order to determine also it's position for various of applications (Fig. 20.).

Burnishing process is capable for improving the resistance to wear, corrosion and oxidation. Furthermore the burnishing process helps to reduce friction up to a critical level, beyond that, cracks are initiated and the friction is increasing [37]. The tribological behavior of technological surfaces are related to the micro-geometry of surfaces. It was observed that surfaces with better wear resistance had negative $R_{\text {sk }}$ and under $3 R_{k u}$ values. The friction is the smallest in those places where $R_{\text {sk }}$ was the lowest [37].

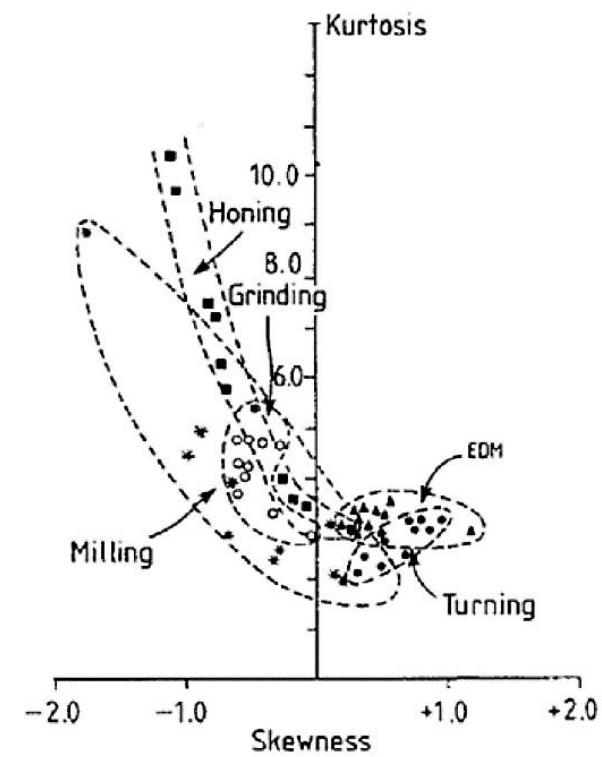

Fig. 19. $R_{\text {sk }}$ and $R_{\text {ku }}$ topological map of surfaces machined with different manufacturing technologies [36]

Fig. 20. shows the topological map of MABB technologies where the red zone is the milling area (before burninshing) and the black is the area after burnishing. So, the surfaces before the MABB machining are the black points and after MABB the red points, consequently, Fig. 20. represents the movement of the two tribology parameters, so, the tribological change of the machined surface.

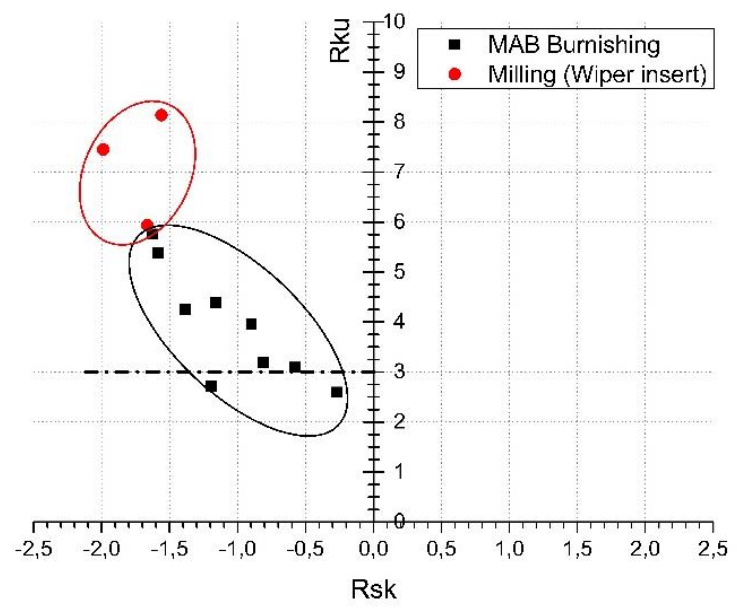

Fig. 20. Topological map of MABB technology 
According to the Fig. 20. the number of 2 and 4 experiments are appropriate in tribological aspect and the 6 and 7 are near the $R_{k u}=3$ line so it is acceptable for subordinate places (e.g. conventional machine' sledge), too. It should be noted that the resulted surfaces of milling are also near the $\mathrm{R}_{\mathrm{ku}}=3$ line because the applied inserts had Wiper geometry. This geometry can produce better surface quality than a conventional insert with similar feed parameter, but it requires special, prescribed axial depth [38]. This positions of the burnished surfaces represent charactteristics with specially useful surfaces under extreme fine applications.

\section{Conclusions}

The aim of this paper is to analyze the optimum gap for Magnetic Assisted Ball Burnishing (MABB) and to determine the optimal machining parameters in order to prove that the introduced novel tool is a promising solution for MABB machining.

Calculation and experiments were used for analysing the rotating dynamometer. Both of methods gave the optimum gap, furthermore it was determined using the KISTLER rotating dynamometer that the burnishing force of $80 \mathrm{~N}$ per ball is resulted.

As shown in Fig. 9. the influence of gap is significant because $1 \mathrm{~mm}$ displacement of the tool means about $50-80 \mathrm{~N}$ force reduction.

The authors formulated the following conclusions:

1. The optimal working gap to create low surface roughness are between 8,5 and 11,5 according to Fig. 13. and Table 4.

2. The optimal working gap to achieve the maximum burnishing force is $\mathrm{h}=10 \mathrm{~mm}$.

3. To manufacture low $\mathrm{R}_{\mathrm{a}}$ surface roughness the feed has the highest effect.

4. In tribological aspect the MABB processing under certain condition is able to produce fine surfaces.

5. Compared to the MABB process with grinding, the machined surface quality is an order better in tribological aspect (Fig. 19. and 20.)

Based on these results, it has been proved that the $M A B B$ tool is promising for roller burnishing flat or (thanks to the flexible balls fixing) near-to-flat (3D harmonic surfaces with flat extension) surfaces. The positions of the resulted burnished surfaces represent charactteristics being especially useful under extreme fine applications.

\section{Acknowledgements}

The research reported is supported by the European Commission through the H2020 project EPIC under grant No. 739592

\section{References}

[1] Goutam D. Revankar, Raviraj Shetty, Shrikantha S. Rao, Vinayak N. Gaitonde: Analysis of surface roughness and hardness in ball burnishing of titanium alloy, Measurement 58 (2014) pp.:256-268

[2] A.M. Hassan, The effects of ball and roller burnishing on the surface roughness and hardness of some non-ferrous metals, J. Mater. Process Technol. 72 (1997) 385-391

[3] M. Okada, M. Shinya, H. Matsubara, H. Kozuka, H. Tachiya, N. Asakawa, M. Otsu: Development and characterization of diamond tip burnishing with a rotary tool, Journal of Materials Processing Technology 244 (2017) pp.:106-115

[4] A. .Zammit, S.Abela, L.Wagner, M.Mhaede, M.Grech. Tribological behaviour of shot peened $\mathrm{Cu}-\mathrm{Ni}$ austempered ductile iron, Wear 302 (2013) pp.: 829-836

[5] Y. C. S. Yinggang Tian. Laser-assisted burnishing of metals, International Journal of Machine Tools \& Manufacture (2006) pp. $14-22$

[6] N. H. Loh: Effects of ball burnishing parameters on surface finish a literature survey and discussion, Prec. Eng. 10 (1988) 215-220

[7] Ecoroll Corporation prospect: Tools \& Solutions for Metal Surface Improvement. Milford, USA, (2006) pp.: 6-31

[8] G. Gomez-Gras, J.A. Travieso-Rodriguez, R. Jerez-Mesa: Experimental characterization of the influence of lateral pass width on results of a ball burnishing operation. The Manufacturing Engineering Society International Conference, MESIC 2015 Procedia Engineering 132, (2015) pp.: 686-692

[9] P. Balland, L. Tabourot, F. Degre, V. Moreau: Mechanics of the burnishing process. Precision Engineering 37 (2013) pp.: 129-134

[10] T. Hryniewicz, K. Rokosz: Corrosion behavior of C45 carbon steel after roller burnishing. metal (2005) pp.: 24-26

[11] R. Rajasekariah, S. Vaidyanathan: Increasing the wear-resistance of steel components by ball burnishing. Wear (1975) pp.: 183-188

[12] N.H. Loh, S.C. Tam, and S. Miyazawa, A Study of the Effect of Ball-Burnishing Parameters on Surface Roughness Using Factorial Design, J. Mech. Work. Technol 18 (1989) pp 53-61

[13] F. Gharbi, S. Sghaier and T. Benameure: Effect of burnishing parameters on surface quality and ductility of Aluminum 1050A rolled sheet by a newly designed ball burnishing tool. 4th Congrès International Conception et Modélisation des Systèmes Mécaniques CMSM (2011) pp.: 1-8

[14] Y.Q. Wang, S.H. Yin, H. Huang, F.J. Chen, G.J. Deng: Magnetorheological polishing using a permanent magnetic yoke with straight air gap for ultra-smooth surface planarization. Precision Engineering 40 (2015) pp.: 309-317

[15] T. Furuya, Y. Wu, M. Nomura, K. Shimada, K. Yamamoto: Fundamental performance of magnetic compound fluid polishing liquid in contact-free polishing of metal surface. journal of materials processing technology 201 (2008) pp.: 536-541 
[16] S. Yin, T. Shinmura: A comparative study: polishing characteristics and its mechanisms of three vibration modes in vibration-assisted magnetic abrasive polishing. International Journal of Machine Tools \& Manufacture 44 (2004) pp.: 383-390

[17] Dhirendra K. Singh1, V.K. Jain, V. Raghuram: Parametric study of magnetic abrasive finishing process. Journal of Materials Processing Technology 149 (2004) pp.: 22-29

[18] Dhirendra K. Singh, V.K. Jain, V. Raghuram, R. Komanduri: Analysis of surface texture generated by a flexible magnetic abrasive brush. Wear 259 (2005) pp.: 1254-1261

[19] János Kodácsy, József Danyi, András Szabó, György Fülöp Magnetic aided roller burnishing metal parts. 7th International Conference on Deburring and Surface Finishing, UC Berkeley, USA (2004) pp.: 375-378

[20] A.M. Hassan, H.F. Al-Jalil, A.A. Ebied: Burnishing force and number of ball passes for the optimum surface finish of brass components. Journal of Materials Processing Technology 83 (1998) pp.: 176-179

[21] E. I. Bernicker: Efficient lubrication of shaft burnishing operations Wear (1971) pp.: 260

[22] A.M. Hassan, A.S. Al-Bsharat, Influence of burnishing process on surface roughness, hardness and microstructure of some non-ferrous metals, Wear 199 (1996) pp.: 1-8

[23] J. Kodácsy, J. Líska: Magnetic Assisted Roller Burnishing and Deburring of Flat Metal Surfaces. Advanced Materials Research Vol. TransTech 472-475 Publication Ltd, Zürich (2012) pp.: 908 911

[24] M.M. El-Khabeery, M.H. El-Axir: Experimental techniques for studying the effects of milling roller-burnishing parameters on surface integrity. International Journal of Machine Tools \& Manufacture 41 (2001) pp.: 1705-1719

[25] P.S. Dabeer, G.K. Purohit, Effects of ball burnishing parameters on surface roughness using response surface methodology, Adv. Prod. Eng. Manage. 5 (2010) pp.: 111-116

[26] J.N. Malleswara Rao, A. Chenna Kesava Reddy, J.N. Rama Rao, Experimental investigation of the influence of burnishing tool passes on surface roughness and hardness of brass specimens, Indian J. Sci. Technol. 4 (9) (2011) 1113-1118

[27] A.M. Hassan, The effects of ball and roller burnishing on the surface roughness and hardness of some non-ferrous metals, J. Mater. Process Technol. 72 (1997) 385-391
[28] KISTLER. http: www.kistler.com/hr/en/products/products-byapplications/tool-development-and-assessment-

products/\#rotating_multi_component_dynamometer_up_to_120 00_1_min_9171_a, 2017.03.20.

[29] Gui-Bin Tan, Shu-Hai Liu, De-Guo Wang, Si-Wei Zhang: Measurement and analysis of wax-oil gel scraping process at contact area under pure sliding conditions, Measurement 80 (2016) pp.: 29-43

[30] Ajit M. Hebbale, M.S. Srinath: Taguchi analysis on erosive wear behavior of cobalt based microwave cladding on stainless steel AISI-420. Measurement 99 (2017) pp.: 98-107

[31] Roy, R. K.: A primer on the Taguchi method, Van Nostrand Reinhold, New York, (1993)

[32] Shan Lou, Xiangqian Jiang, Paul J. Scott: Application of the morphological alpha shape method to the extraction of topographical features from engineering surfaces, Measurement 46 (2013) pp.: 1002-1008

[33] E. S. Gadelmawlaa, M. M. Kourab, T. M. A. Maksoucf, I. M. Elewaa, H. H. Solimand: Roughness parameters, Journal of Materials Processing Technology Vol. 123 (2002) pp. 133-145

[34] G.M. Krolczyk J.B. Krolczyk, R.W. Maruda, S. Legutko, M. Tomaszewski: Metrological changes in surface morphology of high-strength steels in manufacturing processes, Measurement 88 (2016) pp.: 176-185

[35] W. Grzesik, K. Zak: Modification of surface finish produced by hard turning using superfinishing and burnishing operations, Journal of Materials Processing Technologies, Vol. 212 (2012) pp. 315-322

[36] Whitehouse, D.J.: Handbook of surface metrology, Institute of Physics Bristol, UK, (1994)

[37] N.S.M. Ei-Tayeb, K.O. Low, P.V. Brevern, Enhancement of surface quality and tribological properties using ball burnishing process, Mach. Sci. Technol. 12 (2008) pp.: 234-248.

[38] István Biró, Miklós Czampa, Tibor Szalay: Experimental Model for the Main Cutting Force in Face Milling of a High Strength Structural Steel, Periodica Polytechnica Mechanical Engineering Vol. 59 No. 1 (2015), pp.: 16-22 